\title{
La antigüedad de las referencias bibliográficas en publicaciones científicas
}

Antiquity of references in scientific publications

\author{
Alfredo Enrique Oyola-García ${ }^{1}$, Mirtha Gabriela Soto-Cabezas², \\ Melisa Pamela Quispe-llanzo \\ ${ }^{1}$ Natural and Social Sciences Research. \\ ${ }^{2}$ Universidad Nacional San Luis Gonzaga, Ica, Perú.
}

An Fac med. 2014;75(4):381 / doi: http://dx.doi.org/10.15381/anales.v75i4.10863

\section{SR. EDITOR:}

En la práctica diaria es común que los evaluadores de artículos o proyectos de investigación nos pidan referencias bibliográficas con una antigüedad no mayor a cinco años.

Al respecto, Huamaní y PachecoRomero ${ }^{(1)}$-en un estudio de siete revistas médicas peruanas indizadas a SciELO Perú- observaron que el 44,0\% de las referencias bibliográficas tenía una antigüedad menor o igual a cinco años (Índice de Price ${ }^{(2)}$ ). Es decir, cinco o seis de las referencias bibliográficas que se encontraron en estas revistas tenían una antigüedad de seis a más años, llegando a pasar los 50 años, inclusive.

En un estudio de la producción científica publicada por la Revista Panamericana de Salud Pública se observó que el índice de Price alcanzó 20,47\%(3). En otras investigaciones bibliométricas ${ }^{(4-7)}$, este índice varía de $11,69 \%$ a $31,27 \%$. En otro caso ${ }^{(8)}$, la mediana de edad de las referencias bibliográficas fue aproximadamente nueve años. Como vemos, las referencias bibliográficas de las publicaciones científicas, en revistas nacionales e internacionales, con una antigüedad de cinco años o menos no llega al 50\%.
Es innegable que el avance del conocimiento se apoya en investigaciones anteriores ${ }^{(8)}$, pero la exigencia que todas las referencias bibliográficas tengan esta antigüedad en las publicaciones científicas, especialmente en la elaboración de tesis, es una práctica sin sustento y negativa para quienes desarrollan investigación innovadora o en campos donde las publicaciones son escasas.

\section{REFERENCIAS BIBLIOGRÁFICAS}

1. Huamani C, Pacheco-Romero J. Análisis de las referencias bibliográficas en artículos científicos publicados en revistas médicas peruanas 2005 - 2008. An Fac med (internet). 2012 (citado 08 ago 2014); 73(2):135-40. Disponible en: http:// sisbib.unmsm.edu.pe/BVRevistas/anales/v73n2/ pdf/a09v73n2.pdf.

2. Sedeño EE. Indicadores bibliométricos para determinar el envejecimiento de las referencias bibliográficas. Revista Caribeña de Ciencias Sociales (internet). 2013 ene (citado 08 ago 2014). Disponible en: http://caribeña.eumed. net/indicadores-bibliometricos-envejecimientoreferencias-bibliograficas/.

3. Sanz-Valero J, Tomás V, Wanden-Berghe C Estudio bibliométrico de la producción científica publicada por la Revista Panamericana de Salud Pública/Pan American Journal of Public Health en el período de 1997 a 2012. Rev Panam Salud Publica (internet). 2014 (citado 08 ago 2014); 35(2):81-8 Disponible en: http://www.scielosp.org/pdf/rpsp/ v35n2/a01v35n2.pdf.

4. Escorcia-Otálora TA, Poutou-Piñales RA. Análisis bibliométrico de los artículos originales publicados en la revista Universitas Scientiarum (1987-2007).
Universitas Scientiarum (internet). 2008 (citado 08 ago 2014); 13(3): 236-44. Disponible en: http:// www.scielo.org.co/pdf/unsc/v13n3/v13n3a02.

5. Ergul S, Ardahan M, Temel AB, Yildirim BÖ. Bibliometric review of references of nursing research papers during the decade 1994-2003 in Turkey. International Nursing Review (internet). 2010 (citado 08 ago 2014); 57(1): 49-55. Disponible en: http://onlinelibrary.wiley.com/doi/10.1111/j.1466$7657.2009 .00770 . \times$ /abstract; jsessionid $=25576 \mathrm{~B}$ 72E5E465B75A5BD9E6F79BEEFF.f01t02?denie dAccessCustomisedMessage $=$ \&userlsAuthenti cated $=$ false.

6. Tomás-Casterá VT, Sanz-Valero J, Wanden-Berghe C, Landaeta-Jiménez M; Red Mel-CYTED. Revistas de nutrición editadas en Venezuela, indizadas en SciELO, en la primera década del siglo XXI: estudio bibliométrico de la producción científica y de consumo. An Venez Nutr (internet). 2010 (citado 08 ago 2014); 23(2):80-7. Disponible en:http://www. scielo.org.ve/pdf/avn/v23n2/art04.pdf.

7. Tomás-Casterá $\vee$, Sanz-Valero J, Wanden-Berghe C. Estudio bibliométrico de la producción científica de la Revista de Nutrição a través de la Red SciELO (2001 a 2007). Rev. nutr (internet). 2010 sept.-oct (citado 08 ago 2014); 23(5):791-99. Disponible en: http://www.scielo.br/pdf/rn/v23n5/a09v23n5.pdf.

8. Culebras-Fernández J, Garcia de Lorenzo A, Wanden-Nerghe C, Castiel D, Sanz-Valero J. ¡Cuidado!, sus referencias bibliográficas pueden ser estudiadas. Nutr Hosp (internet). 2008 (citado 08 ago 2014); 23(2):85-88. Disponible en: http:// www.aulamedica.es/gdcr/index.php/nh/article/ viewFile/4008/4008.

\section{Corresponsal:}

Alfredo Enrique Oyola-Garcia

Dirección: C.H. A. Valdelomar C-201 - Ica, Perú

Teléfono: 956-124996

Correo electrónico: aoyola@redmed-ica.com 